\title{
The effect of information about fat content on food consumption in overweight/obese and lean people
}

Citation for published version (APA):

Roefs, A., \& Jansen, A. (2004). The effect of information about fat content on food consumption in overweight/obese and lean people. Appetite, 43(3), 319-322. https://doi.org/10.1016/j.appet.2004.05.002

Document status and date:

Published: 01/01/2004

DOI:

10.1016/j.appet.2004.05.002

Document Version:

Publisher's PDF, also known as Version of record

Document license:

Taverne

Please check the document version of this publication:

- A submitted manuscript is the version of the article upon submission and before peer-review. There can be important differences between the submitted version and the official published version of record.

People interested in the research are advised to contact the author for the final version of the publication, or visit the DOI to the publisher's website.

- The final author version and the galley proof are versions of the publication after peer review.

- The final published version features the final layout of the paper including the volume, issue and page numbers.

Link to publication

\footnotetext{
General rights rights.

- You may freely distribute the URL identifying the publication in the public portal. please follow below link for the End User Agreement:

www.umlib.nl/taverne-license

Take down policy

If you believe that this document breaches copyright please contact us at:

repository@maastrichtuniversity.nl

providing details and we will investigate your claim.
}

Copyright and moral rights for the publications made accessible in the public portal are retained by the authors and/or other copyright owners and it is a condition of accessing publications that users recognise and abide by the legal requirements associated with these

- Users may download and print one copy of any publication from the public portal for the purpose of private study or research.

- You may not further distribute the material or use it for any profit-making activity or commercial gain

If the publication is distributed under the terms of Article $25 \mathrm{fa}$ of the Dutch Copyright Act, indicated by the "Taverne" license above, 


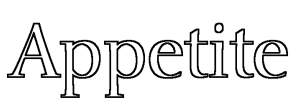

Appetite 43 (2004) 319-322

www.elsevier.com/locate/appet

Brief Communication

\title{
The effect of information about fat content on food consumption in overweight/obese and lean people
}

\author{
Anne Roefs*, Anita Jansen \\ Faculty of Psychology (UNS 40), Department of Experimental Psychology, Maastricht University, P.O. Box 616, \\ 6200 MD Maastricht, The Netherlands
}

Accepted 21 May 2004

\begin{abstract}
This study investigated how fat content labels (high-fat vs. low-fat) influence milkshake consumption in obese/overweight people $(n=23)$, as compared to lean people $(n=21)$. Participants 'tasted' two isocaloric milkshakes in a staged taste test on two occasions. On one occasion the milkshakes were labeled high-fat, whereas on the other occasion they were labeled low-fat. The label-effect was in the expected direction of less (estimated future) consumption in the high-fat label condition, but was not significant for the current consumption and not different between groups. Unexpectedly, order (label high-fat first vs. label low-fat first) had a large effect on consumption.

(C) 2004 Elsevier Ltd. All rights reserved.
\end{abstract}

Keywords: Obesity; Fat content information; Effects of novelty

High-fat foods are especially 'threatening' for your figure because these high-fat foods contain more than twice as much energy than other macronutrients (fat: $9 \mathrm{kcal} / \mathrm{g}$, carbohydrates and proteins: $4 \mathrm{kcal} / \mathrm{g}$ ). Given that health aspects and weight concerns are important factors in determining food choice (Wardle, 1993), knowing that a food is high-fat may inhibit consumption. In fact, several studies have attempted to measure the effect of information about the fat content of the food on consumption. In general, these studies (Caputo \& Mattes, 1993; Shide \& Rolls, 1995; Wardle \& Solomons, 1994) suggest that people adjust their consumption to the expected fat content in that they consume less when they think the food or preload is high-fat.

Moreover, in several studies the effect of information about fat content on palatability and health ratings was considered. Most studies found a positive effect of a high-fat label on palatability ratings (Kähkönen \& Tuorila, 1998; Tuorila, Cardello, \& Lesher, 1994; Tuorila, Kramer, \& Engell, 2001; Wardle \& Solomons, 1994; Westcombe \& Wardle, 1997) but some of them found lowered palatability ratings for a high-fat label (Bowen, Green, Vizenor, Kreuter, \& Rolls, 2003; Bowen, Tomoyasu, Anderson,

\footnotetext{
* Corresponding author.

E-mail address: a.roefs@psychology.unimaas.nl (A. Roefs).
}

Carney, \& Kristal, 1992; Eiser, Eiser, Patterson, \& Harding, 1984). This latter effect might be due to socially desirable answering tendencies, in that it could be seen as socially desirable in this society to report a dislike of high-fat foods. Several studies showed that foods labeled 'high-fat' were also considered as less healthy (Eiser et al., 1984; Engell, Bordi, Borja, Lambert, \& Rolls, 1998).

This effect of a reduced consumption and lower palatability ratings caused by labeling the foods as highfat, might be especially pronounced for overweight or obese people. Admittedly, they may specifically like the taste of high-fat foods (Drewnowski, Kurth, Holden-Wiltse, \& Saari, 1992; Mela \& Sacchetti, 1991; Rissanen et al., 2002), but they also often score high on restraint (Fairburn $\&$ Cooper, 1993). In other words, they are often concerned with their body, weight, and food, and have often undertaken at least several diet attempts. It is likely that they have tried to avoid high-fat foods in these diets. Moreover, a study by Roefs and Jansen (2002) showed that obese and normal weight participants had negative associations with high-fat foods, which were most pronounced for the obese group.

In the current study we will examine if these stronger negative associations with high-fat foods and higher restraint scores will translate to a stronger effect of information about fat content on consumption and 
palatability ratings of milkshakes in a staged taste-test. It is hypothesized that participants will consume less of the milkshakes labeled high-fat than of the milkshakes labeled low-fat, and that this effect will be stronger for the overweight/obese group. For palatability ratings it is hypothesized that the label high-fat will influence the palatability ratings more negatively for the overweight/ obese group than for the lean control group.

\section{Method}

Participants. Participants were 23 overweight/obese (BMI: $M=32.6, \mathrm{SD}=5.4$, Range $=25.9-47.9$ ) and 21 lean (BMI: $M=21.3, \quad \mathrm{SD}=1.8, \quad$ Range $=18.4-24.7$ ) women. BMI refers to body mass index, which is simply the ratio of weight to squared height $\left(\mathrm{kg} / \mathrm{m}^{2}\right)$. This difference in BMI was statistically significant, $t(26.95)=9.46, p<0.001$. Note that the balance we used could weigh people up to a weight of $150 \mathrm{~kg}$. Because, one participant was heavier than $150 \mathrm{~kg}$, we could not determine the exact weight, and we used ' $150 \mathrm{~kg}$ ' for calculating her BMI. One other participant did not want to be weighed, and we based her BMI on self-reported weight. Participants did not differ significantly in age, $t(42)<1$ (overweight/obese: $M=34.0, \quad \mathrm{SD}=9.0 ;$ lean: $M=33.9, \quad \mathrm{SD}=8.5)$. The overweight/obese group $(M=15.5, \mathrm{SD}=3.8)$ scored significantly higher on restraint-evidence of dieting and concern about weight-than the lean control group $(M=9.0, \mathrm{SD}=4.9)$, as measured by the Restraint Scale, $t(42)=4.92, p<0.001$ (Herman \& Polivy, 1980). The overweight/obese group (Global score: $M=1.7, \mathrm{SD}=0.8$ ) also scored significantly higher than the lean control group (Global score: $M=0.8, \mathrm{SD}=0.6$ ) on the presence and severity of specific eating pathology as measured by the Eating Disorder Examination-Questionnaire, $t(1,42)=4.67, p<0.001$ (EDEQ, Fairburn \& Beglin, 1994).

Eight additional participants-not included in the groups described above-were tested in this experiment, but were excluded from analyses because they realized the real purpose of the study in the manipulation check $(n=5)$, or because they took medication for the thyroid gland $(n=1)$, or because they did not show for their second session $(n=2)$.

Procedure. Two isocaloric (400 kcal. each) strawberry flavored milkshakes (400 g each) were prepared each morning. Participants came to the laboratory twice, and these two milkshakes were presented in each session. Prior to their first session participants signed an informed consent form. At the start of both sessions, instructions appeared on a computer monitor. Participants were led to believe that the food industry wanted to test these new dairy products, and that they were going to taste these new products. Depending on condition, the participant was either told that the two dairy products were extra creamy (40\% fat) or low-fat (3\% fat).

Two cans of milkshake ( $400 \mathrm{~g}$ each) in a closed opaque box with a straw for each milkshake, and a small glass of water (appr. $100 \mathrm{ml}$ ) were presented. By putting the milkshakes in an opaque box, the participant could not see what the milkshakes looked like, or how much she had consumed of each milkshake. Participants were told that their task was to judge the milkshakes on several dimensions (e.g., sweetness, palatability) by answering the questions that would appear on the monitor (all 9-point scales). Moreover, the Food Action Rating Scale (FACT) (Aaron, Mela, \& Evans, 1994; Schutz, 1965) was part of the staged taste test. This scale measured intended consumption in the future. This 9 -point scale ranges from ' $1: I$ would only consume this drink if I were forced to' to '9:I would like to consume this drink on every possible occasion'. They were also told that they should try to taste the milkshake before answering each question. Each participant was given exactly 15 minutes for the 'taste test', after which the experimenter returned.

At the end of the first session, participants were just reminded of their next appointment. After finishing the second session, a manipulation check was performed and subsequently participants filled out the Restraint Scale (Herman \& Polivy, 1980) and the EDE-Q (Fairburn \& Beglin, 1994). At the end of the taste test of each session ( $15 \mathrm{~min})$, the experimenter determined the amount of milkshake that was consumed during the taste test. All testing took place in the afternoon; sessions started between 1.00 p.m. and 4.00 p.m. Participants were tested twice within the same week at the same point in time. All participants were asked not to consume any foods within two hours prior to the taste test. Note that two participants (one obese, and one normal weight control) did consume food within two hours prior to the taste test, however, the amount was equal on the two test days. One other participant (obese) consumed two small cookies prior to her first taste-session only (instruction: high-fat). These three participants did not consume foods within one hour prior to the taste test.

Design. All participants took part in two test sessions. In one session they were told that the two milkshakes were extra creamy ( $40 \%$ fat) and in the other session they were told that the two milkshakes were low-fat (3\% fat). All data were analyzed in a 2 (label: label high-fat vs. label lowfat) $\times 2$ (order: session 1 label high-fat vs. session 1 label low-fat) $\times 2$ (group: overweight/obese vs. lean) ANOVA, with repeated measures on the first factor. Order of labels about fat content was counterbalanced over participants. The main dependent variables were the amount of milkshake consumed during the taste test, the intention to consume the milkshakes in the future, and the palatability rating. 


\section{Results}

Consumption during the taste test. An instruction $\times$ order interaction, $F(1,40)=21.38, p<0.001$ superseded a non-significant main effect of instruction, $F(1,40)=2.75$, $p=0.11$. The results did not differ between the two groups, all $F s(1,40)<1.27$. Separate analyses were conducted for each order (label high-fat first vs. label low-fat first). When the milkshakes were labeled high-fat in the first session, participants consumed significantly more of the milkshake labeled low-fat than of the milkshake labeled high-fat, $F(1,21)=19.62, p<0.001$. When the milkshakes were labeled low-fat in the first session, participants consumed significantly more of the milkshake labeled high-fat than of the milkshake labeled low-fat, $F(1,19)=4.47, p<0.05$. See Fig. 1 for relevant means and SEs.

Intention to consume the milkshakes (FACT scale). On average, all participants reported a lower intended future consumption for the milkshake labeled high-fat (overweight/obese: $M=4.2, \quad S D=1.2 ;$ lean: $M=3.9$, $S D=1.7)$ than for the milkshakes labeled low-fat (overweight/obese: $M=4.5, S D=1.5$; lean: $M=4.6$, $S D=1.5), F(1,40)=9.85, p<0.01$. This effect was not different for the two groups, $F(1,40)=1.66, p=0.21$. Note that the reported means are pooled over the factor 'order'.

Palatability ratings. The label did not significantly influence the palatability ratings, $F(1,40)=1.89$, $p<0.18$, and the effects were the same in both groups, all Fs $(1,40)<1.1$ (label HF overweight/obese: $M=5.6$, $S D=1.5$; label LF overweight/obese: $M=5.8, S D=1.3$; label HF lean: $M=5.7, S D=1.3$; label LF lean: $M=5.8$,

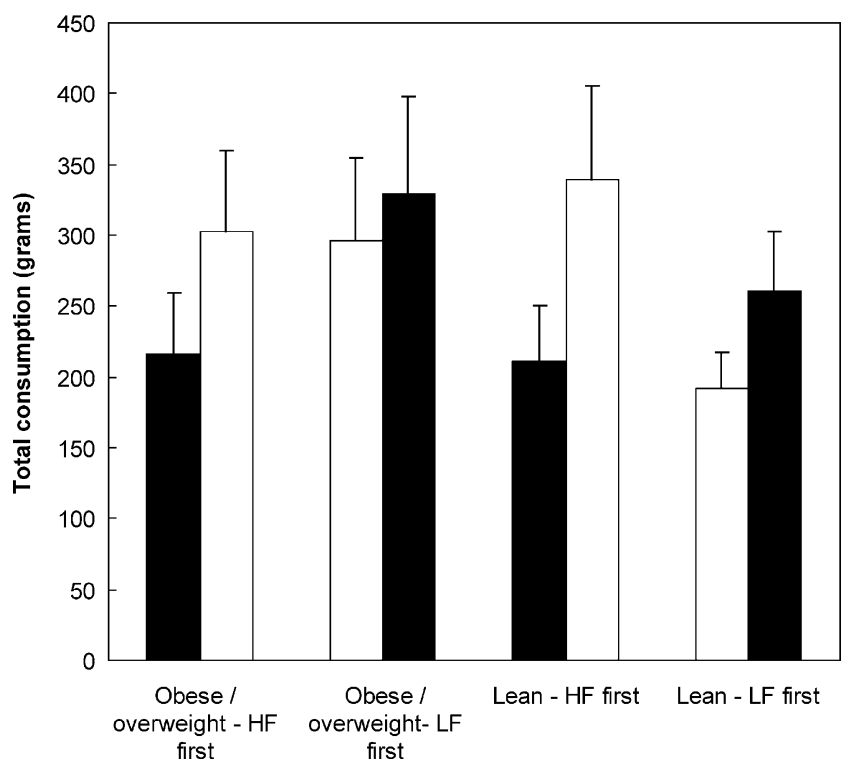

Fig. 1. Total milkshake consumption (gr) as a function of fat-content label, separately for each group (overweight/obese vs. lean) and each order (highfat label first vs. low-fat label first). Error bars represent one standard error. $\mathbf{\square}=$ label high-fat (HF); $\square=$ label low-fat (LF).
$S D=1.5)$. Note that the reported means are pooled over the factor order.

\section{Discussion}

Consumption was hypothesized to be influenced by fat content labels, in that participants were expected to consume less when the milkshakes were labeled high-fat than when they were labeled low-fat. Moreover it was expected that this effect would be especially pronounced for the overweight/obese participants. This would suggest that overweight/obese people worry more about their fat intake, and try to monitor it. The label effect was in the hypothesized direction of less consumption with the highfat label than with the low-fat label. However, this effect was not significant and was not specific or stronger for the overweight/obese group, although power may have been a problem. These results are comparable to a study by Bowen et al. (2003), in which a similar (non-significant) decrease in consumption was found when foods were labeled as high-fat as compared to low-fat. Notably, Bowen et al. (1992), employing a similar methodology, found an opposite effect. Women consumed more of high-fat ice cream when it was labeled high-fat than when it was labeled low-fat. A possible explanation, put forward by Bowen et al. (1992), could be that this group of participants was not particularly weightconscious, and that they based consumption on expectancies of good taste. Notably, energy intake was found to be higher after participants received a lunch or a preload labeled lowfat (Caputo \& Mattes, 1993; Shide \& Rolls, 1995). Furthermore, Wardle \& Solomons (1994) found that participants ate a lower proportion of sandwiches labeled full-fat when they received information about cardiovascular diseases in comparison to a no information control group.

Unexpectedly, the order of the labels (label HF in first session vs. label LF in first session) - that was carefully counterbalanced-played an important role. For the participants that consumed the milkshake labeled high-fat first, consumption on this first occasion was likely inhibited by both the high-fat label and the fact that the situation was novel to them (see Overduin \& Jansen, 1997). The label high-fat may have inhibited consumption by both fear of fatness (restraint) and by expectations of greater satiation. The situation was novel in the sense that they were asked to consume novel dairy products in a novel environment (laboratory). In their second session (milkshakes labeled low-fat), consumption was likely promoted by both the lowfat label and the relative familiarity of the testing situation. The low-fat label may have promoted consumption by both a cognitive disinhibition (low-fat foods are allowed) and a lowered satiation expectation, in that they may have expected that the milkshakes labeled low-fat would be less satiating than the milkshakes labeled high-fat in the previous session. 
For the group of participants that received the milkshakes labeled low-fat in the first session, the effects of novelty and label likely operated in opposite directions. In their first session, the label low-fat likely promoted consumption, whereas the novel test situation likely inhibited consumption. In their second session, the label high-fat may have inhibited consumption, whereas the relative familiarity of the testing situation may have promoted consumption, leading to a higher consumption in the second session (milkshakes labeled high-fat). This significantly higher consumption in the second session suggests that the effects of novelty were a stronger determinant of consumption than the effects of fat content label.

By adding the FACT (Aaron et al., 1994; Schutz, 1965) to our staged taste test, the intended future consumption was measured. The effects for the FACT score were consistent with our hypothesis of less consumption of milkshakes labeled high-fat than of milkshakes labeled low-fat. However, these effects were not different for the overweight/obese as compared to the lean control group. For the palatability ratings, no effects of either label or group were found. Ratings were similar across groups and labels.

In sum, the current results suggest that effects of novelty and fat content label effects may operate together in determining consumption. The effects of novelty may even be stronger than effects of fat content labels in this kind of experiments. For the expected future consumption (FACT) only the fat content label played a role, in that lower ratings were given to the milkshakes labeled high-fat, independent of familiarity with the lab situation.

\section{Acknowledgements}

This study is financed by the Netherlands Research Organization (NWO) Grant 425-20-801, awarded to Anita Jansen. The authors would like to thank Gerard van Breukelen for his advice on the statistical analyses, and Dr John Cooling for providing the recipes for the milkshakes. Moreover, we would like to thank two anonymous reviewers for providing very helpful comments. Correspondence concerning this article should be addressed to: a.roefs@psychology.unimaas.nl [A.Roefs].

\section{References}

Aaron, J. I., Mela, D. J., \& Evans, R. E. (1994). The influences of attitudes, beliefs and label information on perceptions of reduced-fat spread. Appetite, 22, 25-37.
Bowen, D., Green, P., Vizenor, N., Vu, C., Kreuter,, \& Rolls, B. (2003). Effects of fat content on fat hedonics: cognition or taste. Physiology and Behavior, 78, 247-253.

Bowen, D. J., Tomoyasu, N., Anderson, M., Carney, M., \& Kristal, A. (1992). Effects of expectancies and personalized feedback on fat consumption, taste, and preference. Journal of Applied Social Psychology, 22, 1061-1079.

Caputo, F. A., \& Mattes, R. D. (1993). Human dietary responses to perceived manipulation of fat content in a midday meal. International Journal of Obesity, 17, 237-240.

Drewnowski, A., Kurth, C., Holden-Wiltse, J., \& Saari, J. (1992). Food preferences in human obesity: carbohydrates versus fats. Appetite, 18, 207-221.

Eiser, J. R., Eiser, C., Patterson, D. J., \& Harding, C. M. (1984). Effects of information about specific nutrient content on ratings of 'goodness' and 'pleasantness' of common foods. Appetite, 5, 349-359.

Engell, D., Bordi, P., Borja, M., Lambert, C., \& Rolls, B. (1998). Effects of information about fat content on food preferences in pre-adolescent children. Appetite, 30, 269-282.

Fairburn, C. G., \& Beglin, S. J. (1994). The assessment of eating disorders: interview or self-report questionnaire? International Journal of Eating Disorders, 16, 363-370.

Fairburn, C. G., \& Cooper, Z. (1993). The eating disorder examination. In C. G. Fairburn, \& G. T. Wilson (Eds.), Binge eating: Nature, assessment, and treatment (12th ed) (pp. 317-332). New York: Guilford Press.

Herman, C. P., \& Polivy, J. (1980). Restraint eating. In A. J. Stunkard (Ed.), Obesity (pp. 208-225). Philadelphia: Saunders.

Kähkönen, P., \& Tuorila, H. (1998). Effect of reduced-fat information on expected and actual hedonic and sensory ratings of sausage. Appetite, 30, 13-23.

Mela, D. J., \& Sacchetti, D. A. (1991). Sensory preferences for fats: relationships with diet and body composition. American Journal of Clinical Nutrition, 53, 908-915.

Overduin, J., \& Jansen, A. (1997). Conditioned insulin and blood sugar responses in humans in relation to binge eating. Physiology and Behavior, 61, 569-575.

Rissanen, A., Hakala, P., Lissner, L., Mattlar, C. E., Koskenvuo, M., \& Rönnemaa, T. (2002). Acquired preference especially for dietary fat and obesity: a study of weight-discordant monozygotic twin pairs. International Journal of Obesity, 26, 973-977.

Roefs, A., \& Jansen, A. (2002). Implicit and explicit attitudes toward highfat foods in obesity. Journal of Abnormal Psychology, 111, 517-521.

Schutz, H. G. (1965). A food action rating scale for measuring food acceptance. Journal of Food Science, 30, 365-374.

Shide, D. J., \& Rolls, B. J. (1995). Information about the fat content of preloads influences energy intake in healthy women. Journal of the American Dietetic Association, 95, 993-998.

Tuorila, H., Cardello, A. V., \& Lesher, L. L. (1994). Antecedents and consequences of expectations related to fat-free and regular-fat foods. Appetite, 23, 247-263.

Tuorila, H., Kramer, F. M., \& Engell, D. (2001). The choice of fat-free vs. regular-fat fudge: the effects of liking for the alternative and the restraint status. Appetite, 37, 27-32.

Wardle, J. (1993). Food choices and health evaluation. Psychology and Health, 8, 65-75.

Wardle, J., \& Solomons, W. (1994). Naughty but nice: a laboratory study of health information and food preferences in a community sample. Health Psychology, 13, 180-183.

Westcombe, A., \& Wardle, J. (1997). Influence of relative fat content information on responses to three foods. Appetite, 28, 49-62. 